\title{
Classification of different types of metal from recyclable household waste for automatic waste separation system
}

Siti Hajar Yusoff, Sazali Mahat, Nur Shahida Midi, Sarah Yasmin Mohamad, Syasya Azra Zaini Department of Electrical and Compiter Engineering, International Islamic University Malaysia, Malaysia

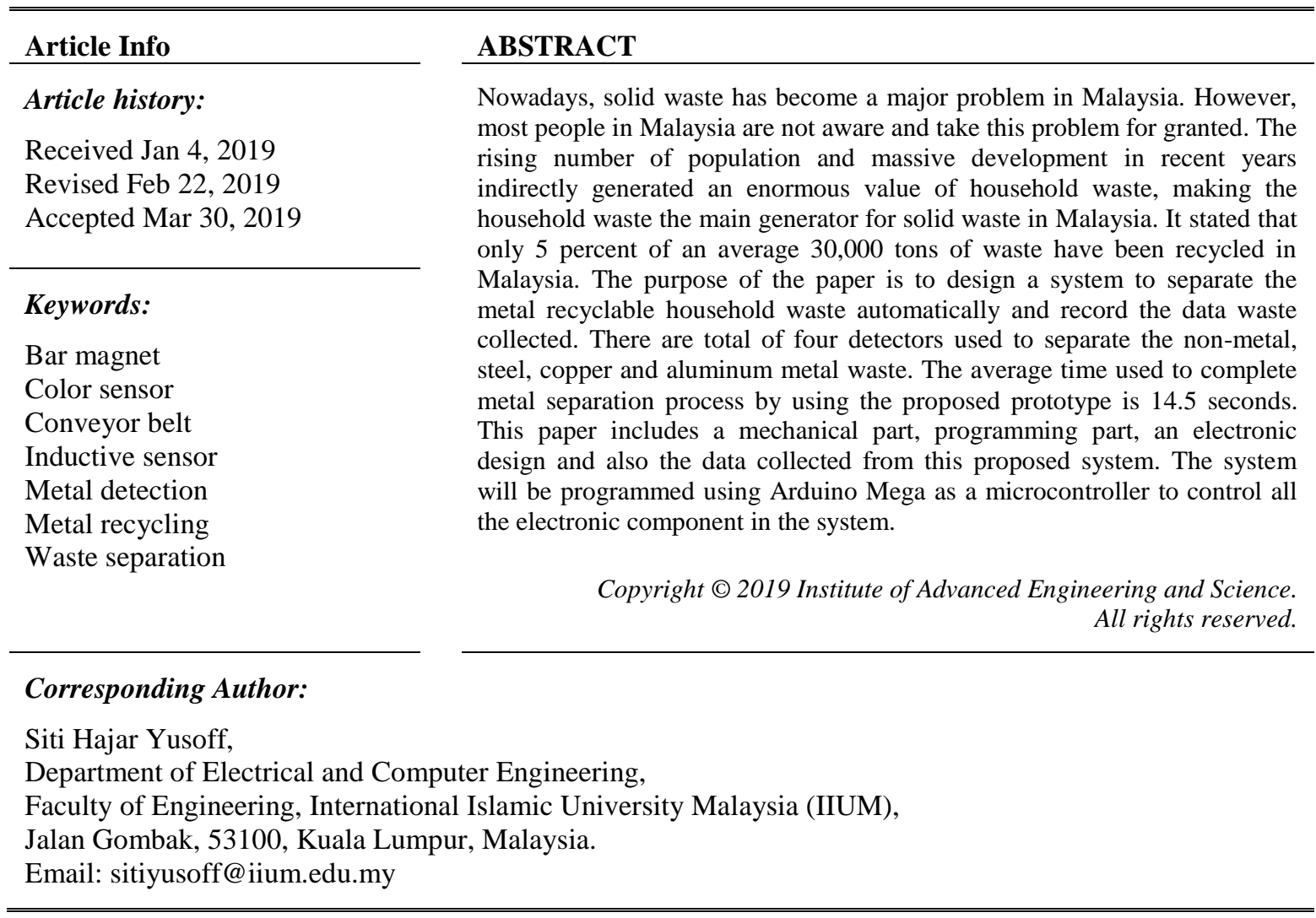

\section{INTRODUCTION}

Nowadays, solid waste has become a major problem in Malaysia. However, most people in Malaysia are not aware and take this problem for granted. The rising number of population and massive development in recent years indirectly generated an enormous value of household waste, making the household waste the main generator for solid waste in Malaysia. It stated that only 5 percent of an average 30,000 tons of waste have been recycled in Malaysia [1]. As a result, all the solid waste that has been produced will directly transfer to the landfill.

The National Solid Waste Management Policy intends to inaugurate a solid waste management system which is integrated, comprehensive, profitable and viable while being acceptable to the community. GSR Environmental Consultancy Sdn. Bhd. (GSR) was commissioned by Jabatan Pengurusan Sisa Pepejal Negara (JPSPN) to conduct an exhaustive Survey on Solid Waste Composition, Characteristics and Extant Practice of Solid Waste Recycling in Malaysia in July 2011 to overcome the waste management issue [2].

Despite the huge amount and complexity of waste produced, the standards of waste management are still poor especially in Malaysia. Figure 1 shows the various metal material in household. The method used in waste management system is less efficient compared to other developed countries. The usage of waste separation system with its maximum efficiency can increase our country's management waste system. Unfortunately, Malaysian still lack of awareness on this system but there is still $15 \%$ of us who are aware on 
this matter [3]. Therefore, this project is initiated to create an automatic metal sorting system that is more effective, simple and fast to speed up and simplify metal recycling work. Besides, it can reduce the energy used to separate the waste manually [4].

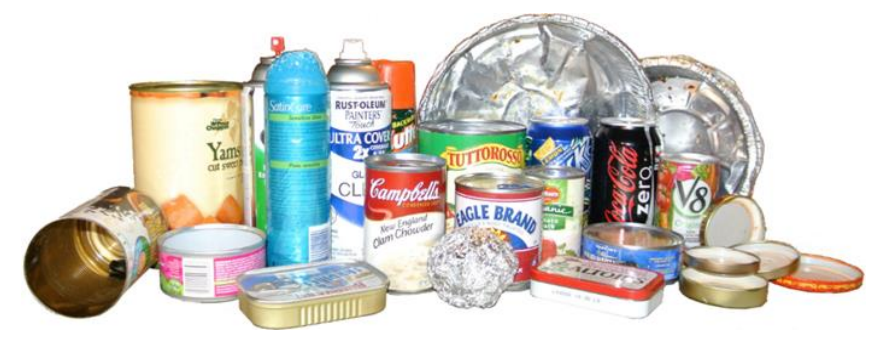

Figure 1. Metal material in household [5]

The proposed system for this project is called Automatic Metal Waste Separator System for recyclable household waste. This machine managed to automatically separate recyclable household waste into four categories which are non-metal, steel metal, aluminium metal and copper metal. The function of this machine is when people want to throw their metal waste material, they just put the material into the machine then the machine will automatically separate the material by its assigned classification. This automatic system will help people to practice recycling and will make the metal recycling industry work easier. The project focused on metal material since it is the most valuable material that is easily recoverable and has the highest value compare to other recycle materials [6].

\section{METHODOLOGY}

Figure 2 portrays the block diagram represents the Automatic Metal Waste Separator where 4 types of materials are segregated namely non-metal, steel metal, copper metal and aluminum metal. The trash is placed on the conveyor which move on the motor of $12 \mathrm{~V}$. All the components are working together and connected to each other through Arduino Mega as microcontroller.

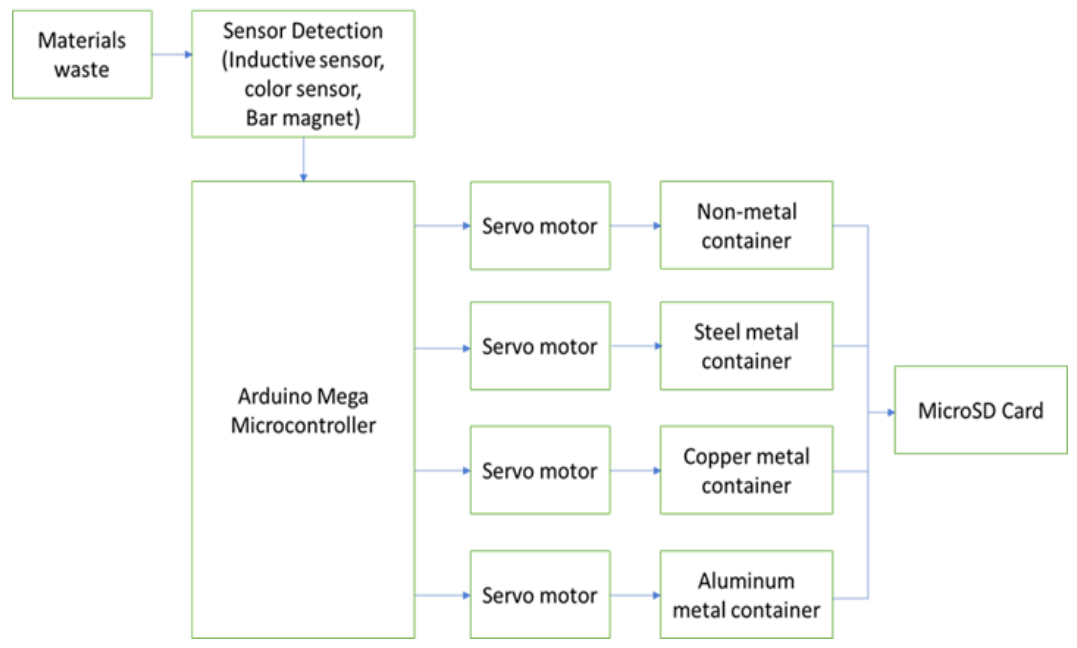

Figure 2. Block diagram of proposed system

Figure 3 and 4 are the image of breadboard and schematic diagram of system for this project. It shows the connection of electronic component that used in this project which are inductive sensor, color sensor, MicroSD Card module, ultrasonic sensor and Arduino Mega [7]. These diagrams have been constructed by using Fritzing software. Arduino Mega will act as a microcontroller which all the sensors and servos will be connected to it. For Inductive sensor 1 (non-metal detector), the pin input signal will be attached at pin 42 while Inductive sensor 2 (aluminum detector) will be attached at pin input 40. For Color sensor, the pin input 
signal for S0 will be attached at pin 38, S1 will be attached at pin 6, S2 will be attached at pin 48, S3 will be attached at pin 46 and OUT will be attached at pin 7. For Ultrasonic sensor, the pin input signal for TRIG pin will be attached at pin 45 and ECHO pin will be attached at pin 47. For MicroSD card module, the pin input signal for MOSI will be attached at pin 51, MISO will be attached at pin 50, SCK will be attached at pin 52 and CS will be attached at pin 53. For Servo 1 (copper pusher), the pin input signal will be attached at pin 2. For Servo 2 (non-metal pusher), the pin input signal will be attached at pin 3. For Servo 3 (aluminum pusher), the pin input signal will be attached at pin 4. For last servo which is continuous 360 degree rotation servo (steel detector), the pin input signal will be attached at pin 5 . The electronic circuit will be active when $5 \mathrm{~V}$ of power supply is on from Arduino.

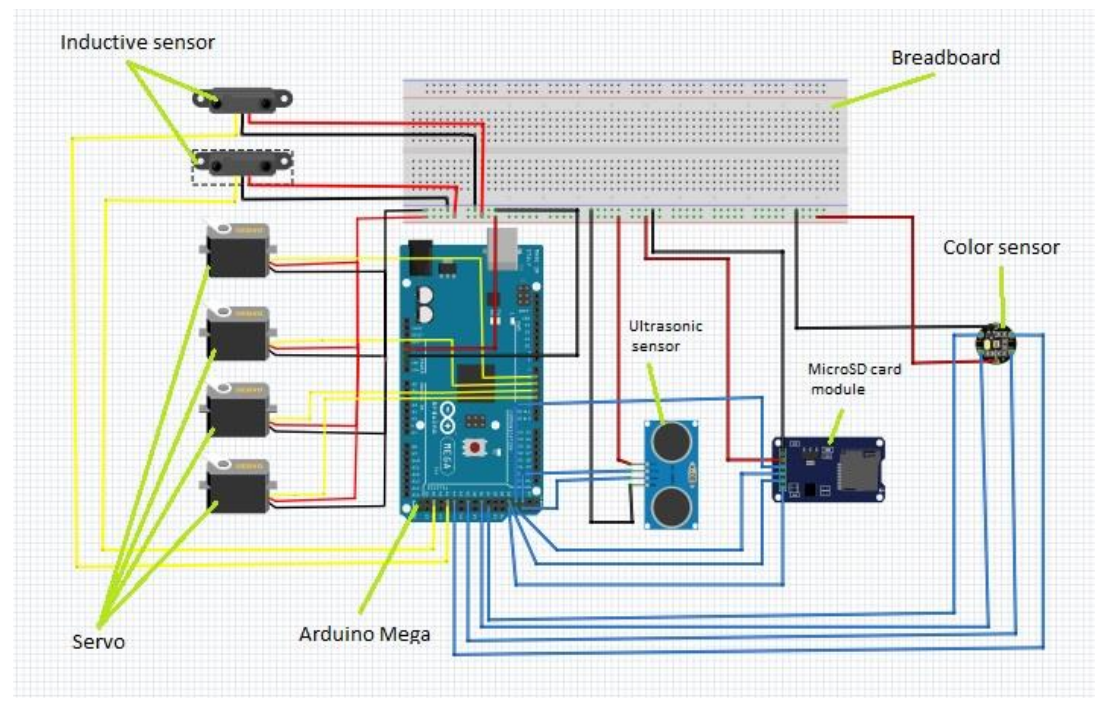

Figure 3. Breadboard diagram of system

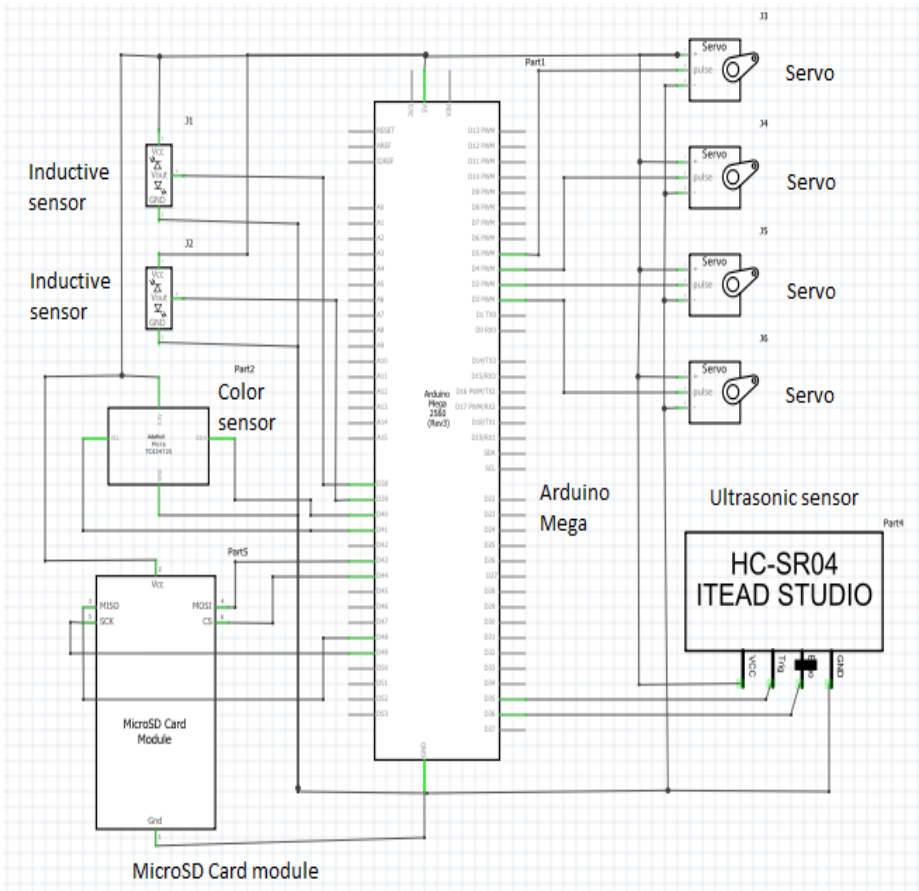

Figure 4. Schematic diagram of system 


\section{HARDWARE DESCRIPTION}

Combination of hardware and software are used in this project to operate the project's system properly. A software, coding's and electronic components make up the prototype of this project.

a. Inductive Sensor

In this project, inductive sensor is used to detect metal object. The sensor does not need to make a contact with the material in order for the sensor to detect the material. The sensor differentiates the metal material according to the distance between the surface of sensor and object [8]. Each metal material has the different value of permittivity, thus this sensor can differentiate the aluminum metal by the value of sensing range.

b. Color Sensor

The color sensor model TCS3200 is used to detect copper metal in this project. Combined usage of these sensors make it is possible to detect and different color [9]. Copper is known for its metallic reddishbrown color. So, color sensor can be used to identify copper metal by its specialist color because other metals have different color from copper.

c. Bar Magnet

Bar magnet is used to detect steel metal. Steel metal has a specialist characteristic compare to other metals because only steel metal can be attached with a magnet. A bar magnet is a rectangular piece of object that made up of iron, steel or any other ferromagnetic substance that shows permanent magnetic properties.

d. Ultrasonic Sensor

The ultrasonic sensor is used to count the quantity of steel metal in container. The sensor will detect the presence of object by measure the distance using ultrasonic waves. The sensor head emits an ultrasonic wave and receives the wave reflected back from the target [10]. The sensor will be active when it detects object in the container if the object is at specified distance that has been set in the coding part.

e. MicroSD Card Module

MicroSD Card Module and MicroSD Card are used to collect a data of material waste in the container. This MicroSD card will save the quantity of material waste in each container from the machine [11]. MicroSD Card Module uses the standard SPI interface for communication, which involve SPI buses, MISO, MOSI, SCK, and a CS signal pin. Through programming, the data can easily be read and wrote into SD Card by using the Arduino Mega as microcontroller.

f. Arduino Mega

Arduino Mega is used as a software to code the program of the system. This software is also known as IDE, Integrated Development Environment which is easy to create the code and then upload the code to the Arduino board [12]. The Arduino is used as the microcontroller that process all the inputs and outputs of the system.

g. Servo Motor $\left(180^{\circ}\right)$

The servo is perfect as a microcontroller in this project for rotate the lids of the waste pushers. Servos have integrated gears and a shaft that can be accurately controlled [13]. Generally, the shaft of servos allows to be positioned at various angles, between 0 and 180 degrees but in this project the servo is set to rotate at 55 degree rotation

h. $\quad$ Servo Motor $\left(360^{\circ}\right)$

The servo is used in this project to rotate the bar magnet continuously at 360 degrees. The difference between Servo Motor $180^{\circ}$ and $360^{\circ}$ is the position angles [14]. This servo motor can be positioned at various angles, between 0 and 360 degrees but in this project the servo is set to rotate continuously at 360 degrees.

\section{i. $12 \mathrm{~V} \mathrm{DC}$ Motor}

A $12 \mathrm{~V}$ motor is used to rotate the roller of the conveyor to move a trash along the conveyor at a constant speed with maximum of 5000RPM. In this project, only 5 Volt is needed to operate the motor at the wanted speed. The motor can sustain certain amount of load which in this project, trash is the load.

\section{DESIGN AND TESTING}

Figure 5 displays the flowchart of Automatic Metal Waste Sorter system. For the first step, the user enters a trash that will go into the conveyor belt of machine. Next, the trash will go through the first detector which is inductive sensor. It will detect either the trash is metal material or not. If the sensor inactive, then the trash will be pushed into non-metal container. While if the sensor active, then the trash will go through the conveyor belt. It will lead to the second detector which is bar magnet that will detect the steel metal. If the trash is a steel metal then the trash will be pushed into a steel container. Then, the Ultrasonic sensor is used to count the quantity of steel metal inside the steel container by detect the distance of object in the container. After that, if the trash is not a steel metal then it will go to the third detector which is color sensor 
that will detect the copper metal. If the trash is a copper metal then it will be pushed into the copper container. The quantity of copper metal inside the copper container is counted by set the coding as when color sensor active, then copper=copper+1. Finally, if the trash is not a copper metal then it will go to the fourth detector which is inductive sensor that will detect the aluminum metal. If the trash is an aluminum metal then it will be pushed into the aluminum container. The quantity of aluminum metal inside the aluminum container is counted by set the coding as when inductive sensor active, then aluminum=aluminum+1. The quantity of all metal in each container will be recorded and saved in MicroSD card. Thus, the process is ended.

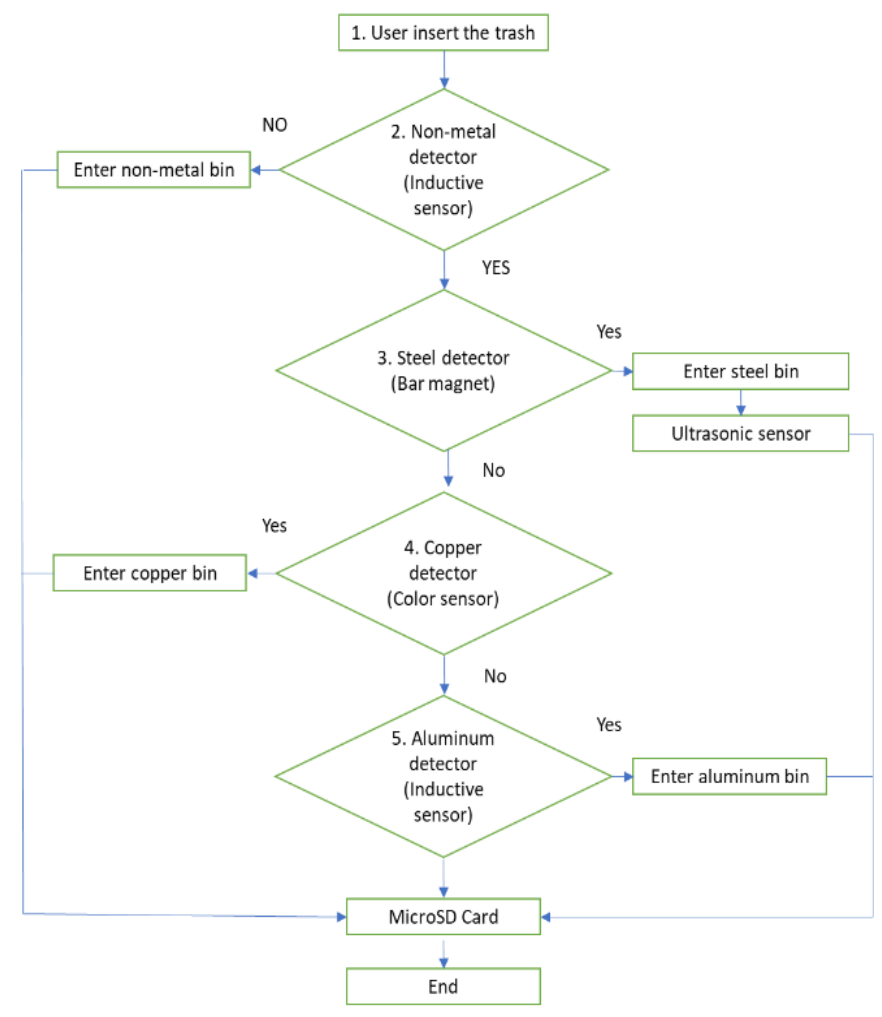

Figure 5. Flowchart of proposed system

\subsection{Component selection}

Table 1 shows the list of all components and materials that will be used in this project with the quantity of each of the components. The components are selected according to project's plan and cost.

Table 1. The list of components

\begin{tabular}{llc}
\hline No & Components & Quantity \\
\hline 1 & Inductive sensor & 2 \\
2 & Color Sensor & 1 \\
3 & Bar magnet & 3 \\
4 & Battery 9V & 1 \\
5 & Ultrasonic sensor & 1 \\
6 & Arduino Uno Mega & 1 \\
7 & Tower Pro Micro servo SG90 $\left(180^{\circ}\right)$ & 3 \\
8 & Tower Pro Servo MG966R $\left(360^{\circ}\right)$ & 1 \\
9 & Breadboard & 1 \\
10 & 12V Motor & 1 \\
11 & Conveyor belt & 1 \\
12 & Trash container & 4 \\
13 & MicroSD Card Module & 1 \\
14 & MicroSD Card & 1 \\
15 & Roller & 2 \\
\hline
\end{tabular}




\subsection{Model and system design}

Figure 6 is the image of model design that has been proposed for this project. It shows the main part of the automatic metal waste sorter system with a dimension. In this machine, there are three main component which are sensor, servo motor and microcontroller. All these components are working together and connected to each other through microcontroller which is Arduino Mega. This model has been constructed by using Solidworks software.

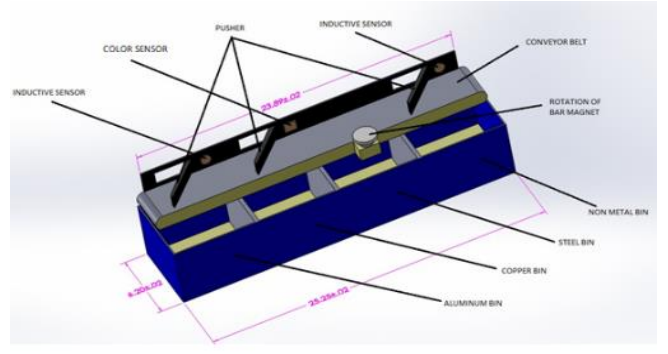

Figure 6. Model design using solidworks software

\subsection{Prototype implementation}

Basically, the product is running by using a conveyor system. Function of this system is to make the movement of material run smoothly through the sensor. A conveyor system also makes a product be more systematic and it is easier to the user because the waste material will run automatically. Experiment that have been done on sensor deduce that the material needs to be near to the sensor closely so that the sensor can detect the presence of material. The design was created a 30 degree of leaning by horizontal on a conveyor to make the material close to the sensor when material run on it. The slider was added on to make the user easy to put the material on the machine and the concept of gravity was used. When the user put the material on slider, it will go down then the conveyor will make the movement of material automatically. Figure 7 shows the detail overview of completed project's prototype.

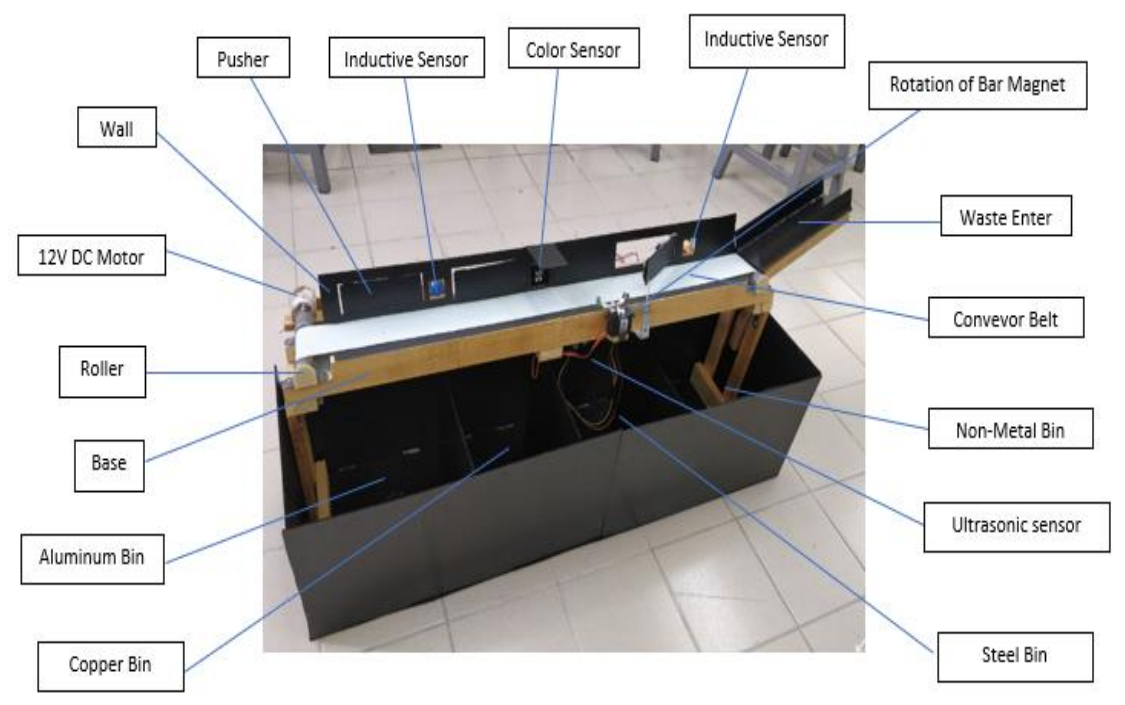

Figure 7. Prototype overview detail

The experiment has been done to test the machine effectiveness. There are 5 types of material used which are bottle plastic, drink can, milk tin, food can and copper wire as shown in Figure 8. Each material was placed on the machine one piece at a time to be tested. The proposed prototype succeeds to differentiate metal waste in 14.5 seconds per pieces. Table 2 portrays the result obtained for this experiment. It shows the machine has separate the materials with exactly according to the types of waste. 


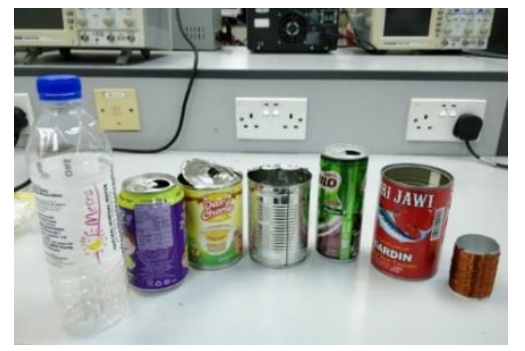

Figure 8. Sample of material waste for experiment

After the materials has been separated, then the data will be collected. The quantity of metal waste in each container will be saved into MicroSD Card memory. The data can be read through computer by inserting the MicroSD Card into the adapter and the data will be showed in txt file. Figure 9 shows the result of quantity waste collected in each metal waste container by using MicroSD Card.

\begin{tabular}{|llll|}
\hline TEST - Notepad & - & \\
File Edit Format View Help & & \\
Steel quantity is 1 & & \\
Copper quantity is 1 & \\
Aluminum quantity is 1 \\
Steel quantity is 2 \\
Aluminum quantity is 2 & & \\
\hline
\end{tabular}

Figure 9. Result of quantity waste collected

Table 2. Result of experiment [6]

\begin{tabular}{ccc}
\hline Number & Types of materials tested & Automatic metal waste container \\
\hline 1 & Bottle plastic & Non-metal container \\
2 & Drink can (ice lemon tea) & Aluminum container \\
3 & Milk tin & Steel container \\
4 & Food can & Steel container \\
5 & Drink can (milo) & Aluminum container \\
6 & Sardine tin & Steel container \\
7 & Copper wire & Copper container \\
\hline
\end{tabular}

\subsection{Experimental on electronic component}

Figure 10 shows the testing on inductive sensor with the metal material. This sensor will give different respond to the conductor material by sensing range and will not respond for non-conductor material [15]. When the metal material (drink can) is near to the sensor, the sensor will respond, and LED will be turn on.

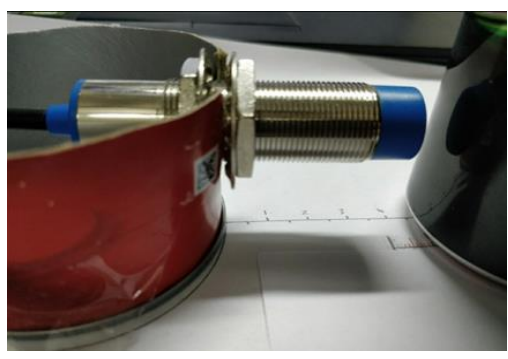

Figure 10. Inductive sensor testing 
Table 3 shows the reading of distance that is obtained when the metal material is near to the inductive sensor. The inductive sensor can detect steel material from far distance which is $7 \mathrm{~mm}$. Next, in the distance of $5 \mathrm{~mm}$ from inductive sensor, aluminium material can be detected. In order to determine the copper metal, the material needs to be placed as near as $2.5 \mathrm{~mm}$ from the sensor.

Table 3. Distance detection on inductive sensor

\begin{tabular}{cccc}
\hline Type of material & Name of material & Detection & Distance $(\mathrm{mm})$ \\
\hline Steel & Food can & Non-metal container & 7 \\
Aluminum & Drinks can & Aluminum container & 5 \\
Copper & Wire & Steel container & 2.5 \\
Non-metal & Paper & Steel container & - \\
\hline
\end{tabular}

Figure 11 portrays the testing of MicroSD Card Module and connected it by using Arduino Mega. This component is used to record the quantity of metal material in each waste container. All the data will be saved permanently in the MicroSD Card memory. While Figure 12 shows the testing of servo MG 90S with the sensor and connected it by using Arduino Mega. After the circuit have been constructed, the servo was tested by touch the material with the sensor, then the sensor will give an input to the Arduino. The Arduino will process the coding that have been set and sent the output information to the servo. The servo will make a rotation of 55 degree when the material touches the sensor. Figure 13 shows the metal material testing run smoothly through the conveyor by using $5 \mathrm{~V}$ of power supply. Figure 14 displays the testing on DC Motor. It will make a full rotation of 360 degree continuously. The motor has been tested by using $5 \mathrm{~V}$ of power supply and it run smoothly on conveyor.

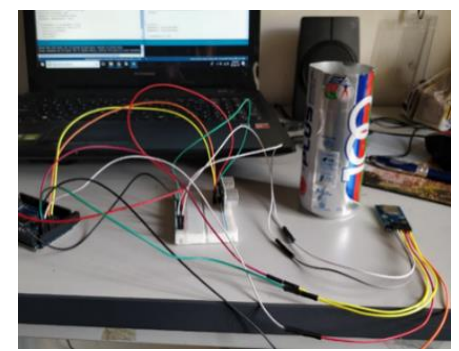

Figure 11. Micro SD card module testing

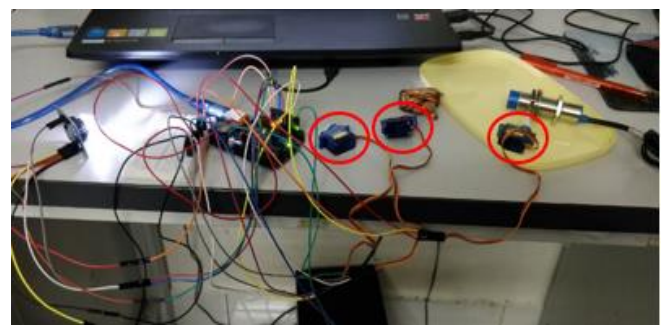

Figure 12. Servo motor testing

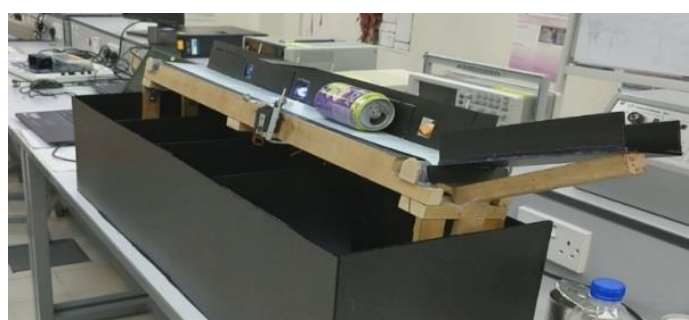

Figure 13. Prototype testing

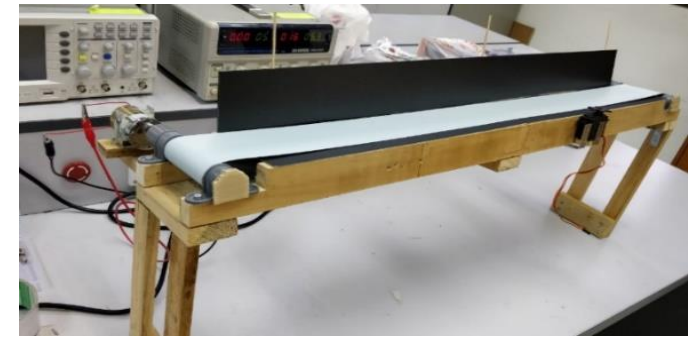

Figure 14. 12V DC motor testing

\subsection{Analysis of survey result}

All the figures show the analysis of the online survey that has been distributed among students and community. An online survey contains some questions regarding the types of metal usage in people household have been conducted. The aim of this survey is to determine the types of metal waste that mostly used by people in their household and the level of people awareness towards metal recycling. Most of the respondents knew and realize meaning of metal recycling and its function. Majority agrees that waste recycling is a good practice in order to take care of our earth specifically our environment [6]. The main problem here is, most of community member only knew but did not practice that metal recycling habit. So, with this product, it might nurture and encourage people in community without boundaries to practice metal recycling. 
The survey contains of 10 simple questions that involved 115 respondents. The data from this survey had been analyzed into charts and statistics. Figure 15 portrays the result of metal recycling habit by community at their home. It shows that most of the community involves in metal recycling with percentage of $65.2 \%$ while another $34.8 \%$ are not practicing it.

Figure 16 displays the result of people involves in waste separation based on their types at their home. It shows that most of the community involves in waste separation according to their types with percentage of $24.3 \%$ while another $75.7 \%$ are not practicing it.

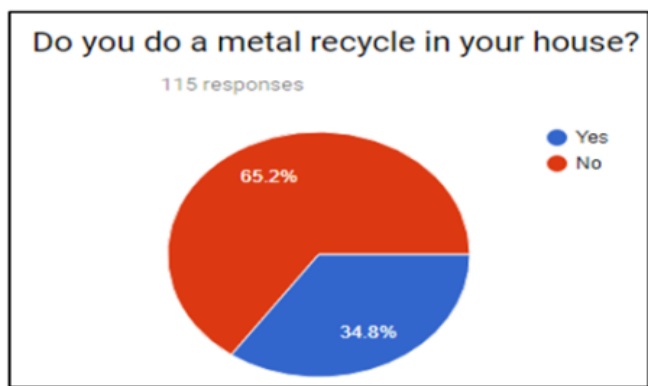

Figure 15. Percentage of metal recycling

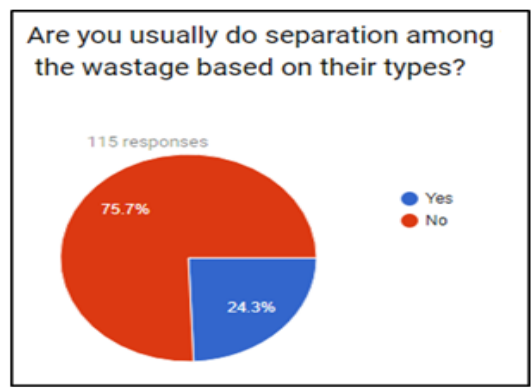

Figure 16. Percentage of people practice a waste separation based on their types

Figure 17 shows the result types of metal waste used by people in their household. It shows the highest metal material used by most of the community is food can, then following it are; drinks can, milk can, tuna can, milo can and lastly copper wire. Figure 18 displays the result quantity of metal waste used by people in a month. It shows that the highest metal material used by most of the community is food can which is 492 , then followed by drinks can which is 440 , milk can which is 391 , tuna can which is 223 , milo can which is 173 and lastly is copper wire which is 99.

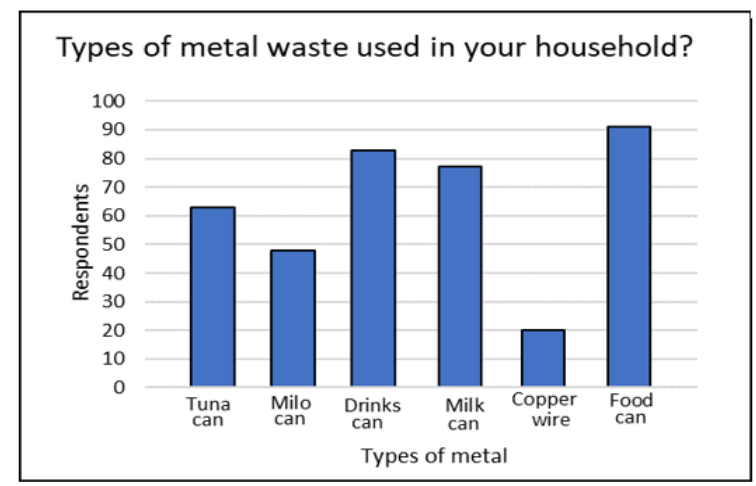

Figure 17. Types of metal waste used in household

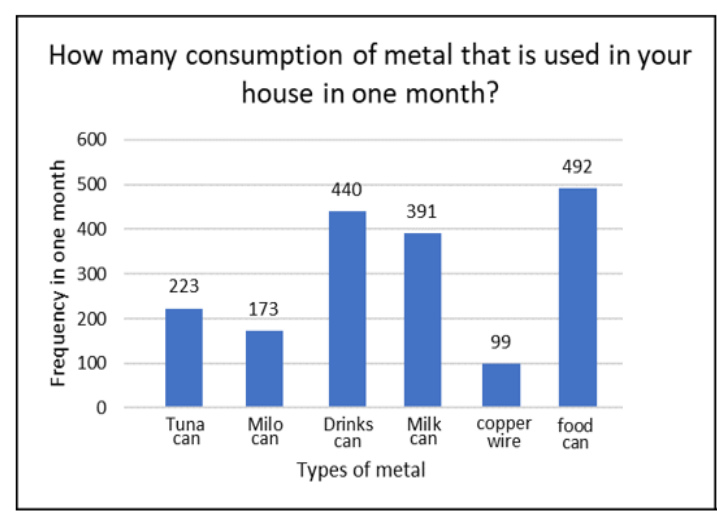

Figure 18. Quantity of metal waste used in one month

\section{CONCLUSION}

This paper has successfully build an Automatic Metal Waste Separator prototype. The system includes both the mechanical part and programming part. The machine will separate the materials into 4 groups which are non-metal, steel metal, aluminum metal and copper metal. After the materials already separated, then the data of quantity materials inside the container will be saved into Micro SD Card. With the existence of this machine, the metal sorting system will be more effective, simple and fast to speed up and simplify metal recycling work. This proposed machine succeeds to complete the metal separation process in average time of 14.5 seconds for one metal. In fact, the existence of the automatic metal waste separator machine is totally a novel approach in increasing the percentage of recycling practice in the community. By 
metal recycling, it can save an energy and resources as it can reduce the demand for raw materials, hence maintain the natural resources for the future. Survey has been conducted in order to know the level of awareness among people in Malaysia regarding metal waste recycling. Most of the respondents agreed it that metal recycling is a good practice in order to take care of the Earth. The main problem here is, most of community member just agree about it but did not practice that metal recycling habit. So, this project has been implemented by expecting it can encourage the people to practice this metal waste recycling.

\section{ACKNOWLEDGEMENTS}

This work was partially supported by Ministry of Higher Education Malaysia (Kementerian Pendidikan Tinggi) under Fundamental Research Grant Scheme (FRGS) number FRGS17-038-0604.

\section{REFERENCES}

[1] C. B. Teo, "Recycling Behaviour of Malaysian Urban Households and Upcycling Prospects," vol. I, no. 1, 2016.

[2] Laman Web Rasmi Jabatan Pengurusan Sisa Pepejal Negara (JPSPN) Retrieved from http://jpspn.kpkt.gov.my/

[3] K. K. Bandar, "Survey on Solid Waste Composition, Characteristics \& MAIN REPORT," Surv. SOlid Waste Compos. Charact. main Rep., 2014.

[4] Tamizharasi, A., Selvathai, J.J., Kavi Priya, A., Maarlin, R., Harinetha, M "Energy aware heuristic approach for cluster head selection in wireless sensor networks". Bulletin of Electrical Engineering and Informatic (BEEI), 2017; 6(1): 70-75.

[5] Rick LeBlanc (2016, december). Introduction to Metal Recycling Retrieved from https://www.thebalance.com/anintroduction-to-metal-recycling-

[6] Sazali Mahat, Siti Hajar Yusoff, Syasya Azra Zaini, Nur Shahida Midi, and Sarah Yasmin Mohamad, "Automatic Metal Waste Separator System", In 2018 7th Int. Conf. Comput. Commun. Eng., 2018, pp. 366-371.

[7] Xtroy.org. (2018) Retrieved from http://xtroy.org/wp-content/uploads/2014/03/Metal-Recycling.jpg

[8] Trainig manual Inductive Sensors, ifm electronic, 2018, pp. 5-12.

[9] GY-31 TCS3200 Color Sensor Recognition Module For Arduino Retrieved from https://www.banggood.com/GY31-TCS3200-Color-Sensor-Recognition-Module-For-Arduino-p-969201.html

[10] ClinchHub. (2018). Ultrasonic Sensor Module HC-SR04 - ClinchHub. Retrieved from https://www.clinchhub.com/product/ultrasonic-sensor-module-hc-sr04/

[11] Author:, M. (2018). Micro SD Card Tutorial. Retrieved from http://www.instructables.com/id/Micro-SDCard-Tutorial/

[12] Siti Hajar Yusoff, Nur Shahida Midi, Sheroz Khan, Majdee Tohtayong. "Predictive control of AC/AC matrix converter". International Journal of Power Electronics and Drive System (IJPEDS), 2017; 8(4): 1932-1942.

[13] TowerPro SG90 Mini Micro Digital Servo 9g For RC Models. Retrieved from https://www.banggood.com/TowerPro-SG90-Mini-Micro-Digital-Servo-9g-For-RC-Models-p-984114.html.

[14] Siti Hajar Yusoff, Ummi Nur Kamilah Abdullah Din, Hasmah Mansor, Nur Shahida Midi, Syasya Azra Zaini. "Design of smart waste bin and prediction algorithm for waste management in household area". Indonesian Journal of Electrical Engineering and Computer Science (IJEECS), 2018; 12(2): 748-758.

[15] Siti Hajar Yusoff, Ummi Nur Kamilah Abdullah Din, Hasmah Mansor, Nur Shahida Midi, Syasya Azra Zaini. "Neural network prediction for efficient waste management in Malaysia". Indonesian Journal of Electrical Engineering and Computer Science (IJEECS), 2018; 12(2): 738-747.

\section{BIOGRAPHIES OF AUTHORS}

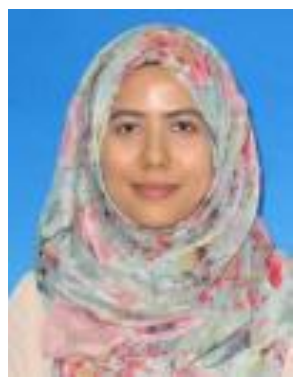

Siti Hajar Yusoff received a MEng. Degree $\left(1^{\text {st }}\right.$ Class Hons) in Electrical Engineering from the University of Nottingham, UK and a Ph.D. degree in Electrical and Electronic Engineering from the University of Nottingham, U.K., in 2009 in 2014, respectively. She has been appointed as an Assistant Professor in the Department of Electrical and Computer Engineering, Faculty of Engineering, International Islamic University Malaysia (IIUM). Her current research interests include IoT (Internet of Things), Smart cities, non-linear control, renewable energy, wireless dynamic charging in electric cars. 

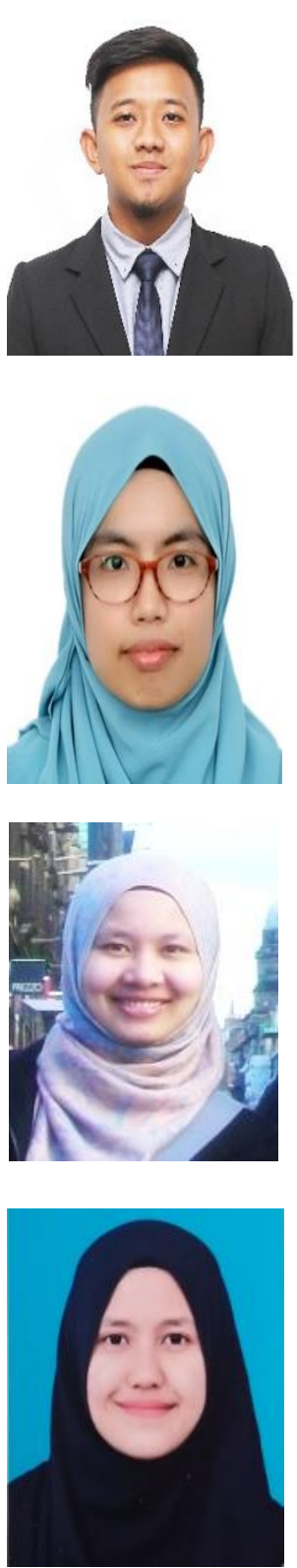

Muhammad Sazali Bin Mahat, degree in Electronics-Computer \& Information Engineering from International Islamic University Malaysia (IIUM), Malaysia. His current research interest is in designing and analyzing sensor detection for different types of metal material on metal waste sorter machine.

Nur Shahida Midi obtained her Doctor of Engineering (Science and Technology) from Tokai University, Japan. She is currently an Assistant Professor at Department of Electrical and Computer Engineering, Faculty of Engineering, International Islamic University of Malaysia (IIUM). Her research interests are high voltage engineering, electrical power engineering, Internet of Things (IoT) and waste management.

Sarah Yasmin Mohamad received a MEng. degree in Communication and Computer Engineering from the Universiti Kebangsaan Malaysia (UKM) and a Ph.D. degree in Electrical and Electronic Engineering from the Queen's University Belfast, Belfast, U.K., in 2011 in 2015, respectively. She has been appointed as an Assistant Professor in the Department of Electrical and Computer Engineering, Faculty of Engineering, International Islamic University Malaysia (IIUM). Her current research interests include antennas and wave propagation and wireless communication systems.

Syasya Azra Zaini received the B.E degree in Electrical and Electronic Engineering majoring in Communication from International Islamic University Malaysia (IIUM), Malaysia in 2018, where she is currently working toward the master's degree. Her research interest are in Internet of Things (IoT) and designing an inductive pad coupler in dynamic wireless power transfer for electric vehicle. 